\title{
Enhancing service quality in public transport systems
}

\author{
G. Beirão \& J. Sarsfield Cabral \\ Faculty of Engineering, University of Porto, Portugal
}

\begin{abstract}
Public transport systems face the challenge of attracting users to fight the lost in market share, mostly due to the increasing use of private cars. Therefore, the concepts of 'quality' and 'customer' must change and the focus must be on meeting people's needs. At the same time, transport systems should be flexible enough to respond to changes in people's requirements and needs. Thus, the aim for public transport must be enhancing quality of the service. This requires a clear understanding of travel behaviour and consumer needs and expectations.

Accordingly, there is an increasing awareness of the importance of including service quality indicators and quality specifications in contracts between operators and public transport authorities. The development of quality measures in the designing of contracts for public transport raises important aspects that must be considered.

This paper examines issues concerning the definition of service quality measures for public transport. This will give a better understanding of pertinent questions and of improvement strategies open to public transport management. Next, it outlines some critical aspects that must be considered when including such measures in contracts between operators and public transport authorities.

Keywords: service quality, public transport, car, travel behaviour, market segmentation, contracts.
\end{abstract}

\section{Introduction}

In the last decades the levels of mobility have increased substantially in all European countries (MOTIF [1]). This raises concern about increasing car use growth and the implications of this in terms of congestion and pollution. Another important feature to be considered in decision making concerning transport is the 
current and changing nature of society and lifestyles. It is necessary to promote measures that can reduce private transport dependence and increase public transport use. This is not an easy task because there is an underlying resistance of people to move from private to public transport (STIMULUS [2]).

Public transport systems need to become more market oriented and competitive. This requires an improvement of service quality, which can only be achieved by a clear understanding of travel behaviour and consumer needs and expectations. Therefore, it becomes essential to measure the level of service in order to identify the potential strengths and weaknesses of public systems. This can provide clues to public transport management in the process of evaluating alternative service improvements aimed at enhancing user satisfaction and increasing market share.

The need to improved service quality contributed to changing public transport. This has occurred in a number of European countries at a legal and organizational level. During the last decade contracting and competitive tendering have spread, being an important feature of the reform of organizational frameworks in European public transport (Van de Velde [3]).

Initially, these changes have been focused on price, which, in some situations, downgraded the quality of the service (QUATTRO [4]). This led to the need of defining and including service quality specifications in competitive tender and contracts. However developing accurate and valid measures of service quality is a complex task, since it deals with perceptions and attitudes. Hence, gaining a better understanding of consumer's perceptions of quality of the service provided by public transport is important. Also, developing quality measures in the designing of contracts for public transport raises important aspects. Quality must be unambiguously specified and monitored.

This paper examines issues concerning the definition of service quality measures for public transport. The focus must be placed on the consumer perspective. This will give a better understanding of pertinent questions and of improvement strategies open to public transport management. Next, it outlines some critical aspects that must be considered when including such measures in contracts between operators and public transport authorities.

\section{Measuring service quality}

The measurement of service quality remains a challenging and important research area with practical implications for service providers, Hensher et al. [5]. Considering public transport, both operators and authorities need to understand how consumers evaluate the quality of the service. However, consumer evaluation of quality is an abstract and elusive concept to measure, Parasuraman et al. [6], making difficult the development of valid and accurate constructs of service quality. It deals with abstract and intangible attributes, such as safety and comfort, which are not easily measured.

From the service providers perspective is essential to identify the most important attributes of service quality that are perceived by current and potential users'. This is the only way to attract more users. However, the specification of a 
set of relevant attributes is complex (Prioni and Hensher [7]). In addition, it is important to identify their relative importance to user's satisfaction. For instance research has shown that reliability (being on time) is a decisive factor [5, 8-11]. The problem is not so much with the waiting, but with the uncertainty of when the transport will arrive (König [8]). Likewise attributes, like frequency [5] and comfort $[5,11,12]$, are also highly valued by consumers, being key elements of consumer satisfaction. Other attributes found as having major negative impact on consumer satisfaction are travel time and fare level (Hensher et al. [5]).

Although those attributes are usually considered very important, others may also have a positive effect on satisfaction and can represent a great potential for improvement. For instance, service providers should make available clear and simple information [9, 12]. Likewise, the driver assumes an important role in consumer contact $[9,12]$. Aspects related to vehicle conditions, (for instance cleanliness) are also meaningful for users [11, 13].

It is important to understand that different user segments evaluate the same service quality area differently and their satisfaction will be influenced by different services attributes (Andreassen [14]). As well, the needs and expectations of users will vary significantly between different segments of the market (QUATTRO [4]).

The process of market segmentation involves the division of the market in several subgroups, each one with unique characteristics, instead of seeing it as one large homogeneous group (Thompson [15]). In public transport market segmentation analysis can be used to identify a number of potential segments with similar attitudes towards the attributes of each transport mode, both for current and potential users. Possible segments to explore could be the ones that show a stronger tendency towards public transport, like occasionally public transport users.

Usually, the market is segmented according to socio-demographic variables and transport use (car users and public transport users). However, it seems that very few differences exist when only socio-demographic segmentation are taken into consideration (Anable [16]), or when groups are segmented according to transport use (STIMULUS [2]). This indicates the need of carefully identifying new segments of users according to the underlying psychological constrains, incorporating perceptions and attitudes. Several studies, using different approaches and techniques have made interesting advances in travel market segmentation $[2,16,17]$.

\section{Understanding travel behaviour}

Understanding travel behaviour and the reasons for choosing one mode of transport over another is an essential issue. However, travel behaviour is complex. For each journey, people have the choice between different transport modes, each one having specific characteristics, advantages and disadvantages, and costs. Additionally the choice of one specific transport mode can vary over time and with the type of journey. Thus, there are many people that use both public transport and private car. So, in order to reduce car use is necessary to 
understand the underlying pattern of travel behaviour. In general, the car is the most attractive mode of transport (STIMULUS [2]). Convenience, speed, comfort and individual freedom are well known arguments (Anable [16]). This means that public transport needs to adjust the service to the attributes required by consumers in order to become more attractive and influence a modal shift (STIMULUS [2]). Service quality is perceived as an important determinant of users' travel demand (Prioni and Hensher [7]).

Several studies confirmed that travel behaviour is influenced by the service level of the transport system. However, this dependence is not directly related to the objective service level, but is influenced by psychological factors (Fujii and Kitamura [18]). Psychological factors include perceptions, attitudes and habits (Ajzen [19], Fujii and Garling [20], Jakobsson et al [21]). So, changing the psychological factors may also change travel mode choice, although the level of service remains the same (Fujii and Kitamura [18]).

Hence, to attract more users to public transport system is important the knowledge of the psychological factors that influence mode choice and measures needed to reduce car dependence. Fujii and Kitamura [18] study the influence of offering a one-month free bus ticket on drivers' attitudes towards bus and it seems to have the potential to change habit, attitude, and travel mode choice. Yet, other measures to reduce car use, like economic discentives do not directly lead to car use reduction, although it affects the motivation to plan car use reduction (Jakobsson et al. [21]). Therefore, in order to reduce car dependence a clear understanding of the natures, extent and causes is needed (Stradling [22]).

\section{Implications for public transport management}

The development of strategies to increase public transport use requires a clear understanding of individual consumer behaviour and a focus on consumer satisfaction. Also, knowledge of perceived service quality of public transport is essential in order to define priority areas of improvement. Such knowledge will guide in the development of strategies aimed at improve satisfaction with the service and become more attractive to users who have other alternatives like car. For instance, knowing the importance to users of treatment by drivers, gives management the information that more attention has to be put on employees customer contact.

Public transport management not always full understands user's wants and expectations (QUATTRO [4]). For that is necessary a market segmentation approach to create homogeneous segments and to be able to respond to each group needs. It is important to acknowledge that different people have different needs and are motivated by different factors. Hence they are affected in different ways by strategies (Anable [16]). Therefore, in the planning process the differences in needs and perceptions have to be recognised. Furthermore, user's needs are dynamic and changes over time and it is necessary to periodically evaluate their evolution and adjust strategies to accommodate the relevant alterations. 
Having a detailed knowledge of users is very important to retain them within the system. Nethertheless, understanding non-users is also crucial because we need to find out the primary reasons for not using public transport, and see if any solution to change behaviour can be implemented. One reason could be the usual unfavourable image associated with public transport, specially the one associated with the bus (Fujii et al. [23]) being important to understand the reasons beyond that. It is known that ease of use, flexibility and giving a sense of freedom are important aspects to car users (STIMULUS [2]). But this can also be a result of an erroneous perception of system performance. Hence, by identifying and then removing potential barriers to public transport usage it may be possible to increase demand. One strategy would be improving public transport image and provide the general public more information about the system, which implies knowing the specific relevant attributes (Tybout et al. [24]).

Other studies $[18,25]$ have shown the possibility for influencing mode choice and alter consumer perceptions by encouraging trial through measures like offering free rides. This shows the potential that implementing policy measures which induces a temporary structural change has on increasing the habit of using public transport use.

Additonaly, others approaches based on market segmentation using psychological factors could be used to appeal to psychological attributes, such as environmental concerns, to influence mode choice (Anable [16]).

Managers must also consider information about the public transport system as an important marketing strategy. For example, quality improvements should be carefully explained, so that public is well informed about changes (and possible problems) introduced by new services (Friman [26]). Hence, service improvements should be visible by the users and properly communicated.

Furthermore, for transport operators the identification of key service quality attributes, not under their directly control is also valuable to influence both transport and local authorities in order to improve public transport attractiveness (Hensher et al. [5]). The priority must be on implementing measures that facilitates public transport circulation.

\section{Quality in public transport contracts}

In the last three decades a number of European countries have experienced significant changes in the legal and organizational frameworks of public transport. Several regulatory regimes varying both in scope and level of control are in practice in urban public transport in Europe. Generally, the organizational frameworks can be identified in three main categories: regulated (publicly owned companies, limited competition models and, deregulated (free market models) (Isotope [27]).

In Europe the dominant position is assumed by publicly owned companies. Yet, one of the main characteristics presented in the reform of organisational forms in European public transport is incontestably the spread of contracting, mostly in combination with competitive tendering (Van de Velde [28]). 
Typically, competitive tendering tends to focus on cost reduction (Hensher and Stanley [29], Johansen et al. [30]). The aim was usually to maintain the existing level of service, but at a lower cost (QUATTRO [4]). Apparently, in public bus transport cost reductions are high (Domberger and Rimmer [31], Muren [32]). While cost efficiency gains are very important, a specified level of service quality must be assured to avoid the degradation of service quality. The inclusion of quality requirements on public transport contracts is still being developed and improved, as new types of contract are enforced and evaluated. In some cases, the level of service provided has not been able to adapt to market requirements. The actual challenge is not to deliver the service at the least cost, but to develop the best possible service in line with economic constraints (Johansen et al. [30]). This points the need for carefully performance specification of the intended operation in order to allocate the roles and responsibilities between the contracting parties.

Generally, the contracts include at least some quality requirements, but they often refer to technical specifications, such as vehicles characteristics. In countries where tendering is more advanced, the quality requirements are linked to pre-fixed values within a bonus/penalty system. This contract often establishes methods for measuring, assessment and control, such as customer satisfaction survey and inspections (QUATTRO [4]).

The challenge is to develop valid service quality indicators that can be incorporated into a performance assessment system. This system should measure service effectiveness from a user perspective, although valuable both to operators and authorities. For the operators it can give an improved understanding of consumers' perceptions and the relative importance of service quality attributes. For authorities is a way to assess the performance (Prioni and Hensher [7]).

It is essential to consider several issues when introducing quality requirements in contracts. Firstly, they must be simple and achievable (Hensher and Prioni [33]). Also, in the design of contracts a number of quality requirements can be included, but it is essential that they are under the operator control. For instance, waiting facilities can be important to users, but they usually belong as a responsibility of local authorities. In addition, is important to establish specific levels and standards of the service the operator must provide to the public and the methods to monitor performance rigorously and effectively. A usual method to evaluate performance is a customer satisfaction survey, associated with penalties and incentives.

It is also important that authorities have enforcement and incentive mechanisms to assure the application of the contract. Domberger and Fernandez [34] analysed the performance of services contracted out by the public sector to private sector organisations. They found that contracts where performance monitoring was adopted had on average better results on service quality ratings by the public. Therefore the pressure of a performance assessment system pushes quality of service to higher standards.

Experience shows that the introduction of quality requirements in contracts can be a way to improve quality in public transport service. However, different types of contracts and competitive tenders have been introduced across Europe 
showing different results and pointing the need to a detailed evaluation of previous experiences.

\section{Conclusion}

Public transport faces the challenge of increasing competition. In order to be an attractive alternative to private car public transport must continuously improve its quality and services delivered to the market. A key factor in achieving this goal is to have highly satisfied users. This implies to grasp their needs and expectations and to be able to satisfy them on regularly bases. Therefore, public transport has to become more consumer oriented.

Across Europe different changes in the legal and organizational frameworks of public transport are occurring. The decrease in public transport market share led to the increasing introduction of quality indicators into competitive tendering and contracting procedures with the objective of increasing the effectiveness of public transport through the delivery of higher quality services (see QUATTRO [4]). Yet, in order to be successful and obtain the intended results, new issues must be considered. For instance, the definition of valid measures for service quality (considering the perspective of users) should be incorporated in a performance assessment system.

On other words, public transport authorities and operators must develop coordinated strategies, tactics and operational measures to enhance service quality. The authors think that, the increase of public transport use can only be based on a clear understanding and focus on the market.

\section{Acknowledgements}

The first author gratefully acknowledges the $\mathrm{PhD}$ grant from Portuguese Foundation for Science and Technology (FCT) under the Program POCTI.

\section{References}

[1] MOTIF, Market Orientated Transport In Focus. Transport Research Fourth Framework Programme, Urban Transport, Office for Official Publications of the European Communities, 2000.

[2] STIMULUS, Segmentation for Transport In Markets Using Latent User Psychological Structures. Transport Research Fourth Framework Programme, Urban Transport, Office for Official Publications of the European Communities, 1999.

[3] Van de Velde, D.M. The evolution of organisational forms in European public transport. Paper present at the 7th Conference on Competition and Ownership in Land Passenger Transport, Molde, Norway, 2001.

[4] QUATTRO, Quality Approach in Tendering Urban Public Transport Operations. Transport Research Fourth Framework Programme, Urban 
Transport, Office for Official Publications of the European Communities, 1998.

[5] Hensher, D.A., Stopher, P. \& Bullock, P., Service quality-developing a service quality index in the provision of commercial bus contracts. Transportation Research Part A: Policy and Practice, 37(6), pp. 499-517, 2003.

[6] Parasuraman, A., Zeithaml, V.A. \& Berry, L.L., A conceptual model of service quality and its implications for future research. Journal of Marketing, 49(4), pp. 41-50, 1985.

[7] Prioni, P. \& Hensher, D.A., Measuring service quality in scheduled bus services. Journal of Public Transportation, 3(2), pp. 51-74, 2000.

[8] König, A., The reliability of the transportation system and its influence on the choice behaviour. Paper presented at the 2nd Swiss Transport Research Conference, Monte Verità, Ascona, March 20-22, 2002.

[9] Edvardsson, B., Causes of customer dissatisfaction - Studies of public transport by the critical-incident method. Managing Service Quality, 8(3), pp. 189-197, 1998.

[10] Bates, J., Polak, J., Jones, P. \& Cook, A., The valuation of reliability for personal travel. Transportation Research Part E: Logistics and Transportation Review, 37(2/3), pp. 191-229, 2001.

[11] Disney, J., Customer satisfaction and loyalty: the critical elements of service quality. Total Quality Management, 10(4/5), pp. 491-497, 1999.

[12] Friman, M. \& Gärling, T., Frequency of negative critical incidents and satisfaction with public transport services. II. Journal of Retailing and Consumer Services, 8(2), pp. 105-114, 2001.

[13] Swanson, J., Ampt, L. \& Jones, P., Measuring bus passenger preferences. Traffic Engineering and Control, 38(6), pp. 330-336., 1997.

[14] Andreassen, T.W., (Dis)satisfaction with public services: the case of public transportation. Journal of Services Marketing, 9(5), pp. 30-41, 1995.

[15] Thompson, M.E. The science and art of market segmentation using PROC FASTCLUS. Prepared for Publication in PNWSUG's 98 Conference Proceedings, 1998.

[16] Anable, J., 'Complacent Car Addicts' or 'Aspiring Environmentalists'? Identifying travel behaviour segments using attitude theory. Transport Policy, 12(1), pp. 65-78, 2005.

[17] Outwater, M., Castleberry, S., Shiftan, Y., Ben Akiva, M., Zhou, Y.S. \& Kuppam, A., Use of structural equation modeling for an attitudinal market segmentation approach to mode choice and ridership forecasting. Paper presented at the 10th International Conference on Travel Behaviour Research, Lucerne, Switzerland, 10-15 August, 2003.

[18] Fujii, S. \& Kitamura, R., What does a one-month free bus ticket do to habitual drivers? An experimental analysis of habit and attitude change. Transportation, 30(1), pp. 81-95, 2003.

[19] Ajzen, I., The theory of planned behavior. Organizational Behavior and Human Decision Processes, 50, pp. 179-211, 1991. 
[20] Fujii, S. \& Garling, T., Application of attitude theory for improved predictive accuracy of stated preference methods in travel demand analysis. Transportation Research Part A: Policy and Practice, 37(4), pp. 389-402, 2003.

[21] Jakobsson, C., Fujii, S. \& Gärling, T., Effects of economic disincentives on private car use. Transportation, 29(4), pp. 349-370, 2002.

[22] Stradling, S.G., Reducing car dependence. Integrated Futures and Transport Choices, Hine, J. and Preston, J. (Eds.), Ashgate Publications, pp. 100-115, 2003.

[23] Fujii, S., Gärling, T. \& Kitamura, R., Changes in drivers’ perceptions and use of public transport during a freeway closure: Effects of temporary structural change on cooperation in a real-life social dilemma. Environment and Behavior, 33(6), pp. 796-808, 2001.

[24] Tybout, A.M., Hauser, J.R. \& Koppelman, F.S., Consumer oriented transportation planning: an integrated methodology for modeling consumer perceptions, preferences, and behavior. Advances in Consumer Research, 5(1), pp. 426-434, 1978.

[25] Bamberg, S., Ajzen, I. \& Schmidt, P., Choice of travel mode in the theory of planned behavior: the roles of past behavior, habit, and reasoned action. Basic and Applied Social Psychology, 25(3), pp. 175-188, 2003.

[26] Friman, M., Implementing quality improvements in public transport. Journal of Public Transportation, 7(4), pp. 49-65, 2004.

[27] ISOTOPE, Improved Structure and Organisation For Urban Transport Operations of Passengers in Europe. Transport Research Fourth Framework Programme, Urban Transport, Office for Official Publications of the European Communities, 1997.

[28] Van de Velde, D., Regulation and competition in the European land transport industry: some recent evolutions. Paper presented at the 8th Conference on Competition and Ownership in Land Passenger Transport, Rio de Janeiro, Brasil, 14-18 September, 2003.

[29] Hensher, D.A. \& Stanley, J., Performance-based quality contracts in bus service provision. Transportation Research Part A: Policy and Practice, 37(6), pp. 519-538, 2003.

[30] Johansen, K.W., Larsen, O.I. \& Norheim, B., Towards achievement of both allocative efficiency and X-efficiency in public transport. Journal of Transport Economics and Policy, 35(3), pp. 491-511, 2001.

[31] Domberger, S. \& Rimmer, S., Competitive tendering and contracting in the public sector: A survey. International Journal of the Economics of Business, 1(3), pp. 439-453, 1994.

[32] Muren, A., Quality assurance in competitively tendered contracts. Journal of Transport Economics \& Policy, 34(1), pp. 99-112, 2000.

[33] Hensher, D.A. \& Prioni, P., A service quality index for area-wide contract performance assessment. Journal of Transport Economics \& Policy, 36(1), pp. 93-113, 2002.

[34] Domberger, S. \& Fernandez, P., Public-Private Partnerships for service delivery. Business Strategy Review, 10(4), pp. 29-39, 1999. 